\title{
Impact of climate change on stratospheric sudden warmings as simulated by the Canadian middle atmosphere model
}

Article

Published Version

McLandress, C. and Shepherd, T. G. (2009) Impact of climate change on stratospheric sudden warmings as simulated by the Canadian middle atmosphere model. Journal of Climate, 22 (20). pp. 5449-5463. ISSN 1520-0442 doi:

https://doi.org/10.1175/2009JCLI3069.1 Available at https://centaur.reading.ac.uk/32033/

It is advisable to refer to the publisher's version if you intend to cite from the work. See Guidance on citing.

To link to this article DOI: http://dx.doi.org/10.1175/2009JCLI3069.1

Publisher: American Meteorological Society

All outputs in CentAUR are protected by Intellectual Property Rights law, including copyright law. Copyright and IPR is retained by the creators or other copyright holders. Terms and conditions for use of this material are defined in the End User Agreement.

www.reading.ac.uk/centaur 
Central Archive at the University of Reading

Reading's research outputs online 


\title{
Impact of Climate Change on Stratospheric Sudden Warmings as Simulated by the Canadian Middle Atmosphere Model
}

\author{
CHARles McLANDRESS AND THEOdORE G. SHEPHERD \\ Department of Physics, University of Toronto, Toronto, Ontario, Canada
}

(Manuscript received 2 February 2009, in final form 12 May 2009)

\begin{abstract}
The dynamics of Northern Hemisphere major midwinter stratospheric sudden warmings (SSWs) are examined using transient climate change simulations from the Canadian Middle Atmosphere Model (CMAM). The simulated SSWs show good overall agreement with reanalysis data in terms of composite structure, statistics, and frequency. Using observed or model sea surface temperatures (SSTs) is found to make no significant difference to the SSWs, indicating that the use of model SSTs in the simulations extending into the future is not an issue. When SSWs are defined by the standard (wind based) definition, an absolute criterion, their frequency is found to increase by $\sim 60 \%$ by the end of this century, in conjunction with a $\sim 25 \%$ decrease in their temperature amplitude. However, when a relative criterion based on the northern annular mode index is used to define the SSWs, no future increase in frequency is found. The latter is consistent with the fact that the variance of $100-\mathrm{hPa}$ daily heat flux anomalies is unaffected by climate change. The future increase in frequency of SSWs using the standard method is a result of the weakened climatological mean winds resulting from climate change, which make it easier for the SSW criterion to be met. A comparison of winters with and without SSWs reveals that the weakening of the climatological westerlies is not a result of SSWs. The BrewerDobson circulation is found to be stronger by $\sim 10 \%$ during winters with SSWs, which is a value that does not change significantly in the future.
\end{abstract}

\section{Introduction}

Stratospheric sudden warmings (SSWs) are by far the most dramatic dynamical events in the Northern Hemisphere winter stratosphere: polar temperatures undergo a rapid increase that reverses the climatological equatorto-pole gradient, causing the westerly flow to become easterly. This typically occurs over a period of about a week, although the effects on the lower stratosphere can last much longer as a result of the long radiative time scales in that region. SSWs are caused by an increase in planetary wave activity propagating upward from the troposphere, and are examples of large-amplitude wavebreaking events that either displace the vortex off the pole (wave-1 warmings) or break it in two (wave-2 warmings).

In addition to being prime examples of wave-mean flow interaction, and thereby of interest in their own

Corresponding author address: Charles McLandress, 60 St. George St., Department of Physics, University of Toronto, Toronto, ON M5S 1A7, Canada.

E-mail: charles@atmosp.physics.utoronto.ca right, SSWs have other important effects. They play an important role in the photochemistry of the ozone layer. During winters without SSWs, the vortex is cold and stable, permitting the formation of polar stratospheric clouds (PSCs), which activate chlorine and lead to chemical ozone loss in the presence of sunlight. By contrast, winters with SSWs are characterized by a stratosphere that is too warm for PSCs to form, thus closing down that pathway for springtime ozone destruction. There is also increasing evidence that SSWs can have an impact on the troposphere. For example, Baldwin and Dunkerton (2001) found that the effects of major SSWs could be seen in surface pressure and storm tracks.

Thus, possible changes in SSWs resulting from climate change would have an effect on ozone recovery and on Arctic ozone more generally. Because chemistry climate models (CCMs) are the only tools available for predicting the future evolution of climate change and ozone recovery in the middle atmosphere, it is important that they be able to get the SSWs right. Charlton et al. (2007) intercompared six stratosphere-resolving models and found that most produced fewer SSWs than are observed. Moreover, none of the models were able to 
capture the midwinter frequency maximum of SSWs. These deficiencies could, in principle, affect the amount of simulated ozone loss in the Northern Hemisphere and lead to an incorrect prediction of future changes. To date there has only been one comprehensive study of the impact of climate change on SSWs. Using an ensemble of transient climate change simulations from a single CCM, Charlton-Perez et al. (2008) found a small positive trend in the frequency of SSWs over the course of this century, with the largest increase occurring in late winter. However, the cause of this predicted increase was unclear.

There is now a general consensus among CCMs that climate change will strengthen the Brewer-Dobson circulation (BDC) as a result of increased stratospheric wave drag (Butchart et al. 2006). McLandress and Shepherd (2009) showed that at mid- to high latitudes the predicted increase in wave drag in their model simulations is due to vertically propagating stationary planetary waves. It is therefore possible that increased planetary wave activity emanating from the troposphere could be responsible for the increased frequency of SSWs found by Charlton-Perez et al. (2008).

Another possible reason for the predicted future increase in SSWs found by Charlton-Perez et al. (2008) relates to how SSWs are identified. Typically, the standard definition for major SSWs based on the zonal mean zonal winds is employed, as was done by those authors. Because this is an absolute criterion, future changes in the climatological mean winds could result in changes in the frequency of SSWs simply by changing the magnitude of the anomaly needed to satisfy the SSW criterion. It is therefore important to understand whether the future statistics of SSWs would change if a relative criterion were employed. In their study of the life cycle of SSWs, Limpasuvan et al. (2004) used empirical orthogonal functions (EOFs) to identify SSWs. Because that method uses a relative criterion to identify SSWs that is based on anomalies, changes in the underlying climatology cannot, on their own, lead to changes in frequency of threshold exceedence. Although they did not apply their method to model simulations, such an approach could yield fruitful results.

In this study, we examine multiyear transient simulations generated using the Canadian Middle Atmosphere Model (CMAM), a CCM that simulates climate change, as well as ozone depletion and recovery. These simulations are used to compare the following two methods for identifying SSWs: 1 ) the standard method, which uses an absolute criterion based on the zonal wind, and 2) the northern annular mode (NAM) method, which uses a relative criterion based on the NAM index. We show that a predicted future increase in
SSW frequency found using the standard method is absent when using the NAM method. These differences are attributed to future changes in the climatological mean winds, which in turn are brought about by changes in wave drag that are unrelated to the SSWs. We also quantify changes in variability, and we find that the variability of $100-\mathrm{hPa}$ heat flux (the driving force behind stratospheric variability) is unchanged in the future, while that of polar temperature is only slightly reduced (and only in the upper stratosphere). This shows that the lack of a future change in the frequency of occurrence of SSWs determined using the NAM method is not an artifact of the EOF analysis, but rather is solely the result of using a relative criterion to identify the SSWs.

The goals of this study are therefore to validate the simulated SSWs in CMAM for the present and to examine and interpret future changes in SSWs. In addition, given the importance of stratospheric wave drag in driving the BDC, we also briefly touch on the impact of SSWs on the BDC.

\section{Model description and simulations}

The CMAM is the upward extension of the Canadian Centre for Climate Modelling and Analysis (CCCma) atmospheric general circulation model (Beagley et al. 1997; de Grandpré et al. 2000; Scinocca et al. 2008). It includes a fully interactive stratospheric chemistry module, a comprehensive radiation scheme, and a suite of other parameterizations relevant to physical processes from the earth's surface up to the model lid at $\sim 100 \mathrm{~km}$. Sea surface temperatures and sea ice distributions (SSTs for short) are prescribed. The simulations described here employ 71 vertical levels, having a vertical resolution that varies from several hundred meters in the lower troposphere to $\sim 1.5 \mathrm{~km}$ near $20 \mathrm{~km}$ and to $\sim 2.5 \mathrm{~km}$ above $60 \mathrm{~km}$. In the horizontal direction a T31 spectral resolution is used, corresponding to a spacing of $\sim 6^{\circ}$ on the linear transform grid. A detailed description of this version of the model is given in Scinocca et al. (2008).

Results from two sets of transient simulations are presented here. The first is an ensemble of two simulations for the recent past (1950-2004), the so-called REF1 simulations for the CCM validation activity (CCMVal) for Stratospheric Processes and their Role in Climate (SPARC), described in Eyring et al. (2005). These simulations are constrained by observed SSTs and concentrations of greenhouse gases and ozone-depleting substances. The difference between the two REF1 simulations is that one uses time-varying sulfate aerosol fields in the radiation and chemistry modules. Because this has little impact on the long-term dynamics, the two simulations are considered as a single ensemble for the 
purposes of this study. The REF1 simulations from 13 CCMs were examined in Eyring et al. (2006), with CMAM comparing very favorably with observations and with other models. This conclusion is supported by the grading exercise of Waugh and Eyring (2008), where CMAM received one of the highest grades.

The second set of simulations is an ensemble of three extending from 1950 to 2099, the so-called REF2 simulations. Greenhouse gases and ozone-depleting substances are prescribed according to the REF2 scenario described in Eyring et al. (2005). SSTs are obtained from three transient simulations of a coupled atmosphere-ocean version of the CCCma model under the same greenhouse gas scenario. This approach differs from other modeling groups participating in CCMVal, whose REF2 ensembles were generated from simulations using different initial conditions but a single set of SSTs (Eyring et al. 2007). Using different but equally plausible realizations of the SSTs, as we have done, gives a more realistic estimate of the uncertainty in long-term changes resulting from natural variability. The REF2 simulations from 11 CCMs were intercompared in Eyring et al. (2007), with CMAM found to be representative of the model means. Validation of the climatological zonal mean zonal winds and temperatures and meridional heat fluxes from the CMAM REF2 simulations were presented in McLandress and Shepherd (2009) and were shown to be in good overall agreement with the National Centers for Environmental Prediction-National Center for Atmospheric Research (NCEP-NCAR) reanalysis (hereafter NCEP; see Kalnay et al. 1996). In addition, good overall agreement in the shape and magnitude of histograms of monthly mean Arctic temperatures between NCEP and CMAM is shown in Hitchcock et al. (2009).

\section{Identification of SSWs}

Two methods are used to identify SSWs. The first uses the well-known World Meteorological Organization (WMO) definition based on the zonal mean zonal wind. This was used by Charlton and Polvani (2007), and will be referred to here as the standard method. The second method uses the daily NAM index, and is similar to what was used by Limpasuvan et al. (2004); this will be referred to as the NAM method.

\section{a. Standard method}

Here, a SSW is defined to occur when the daily average zonal mean zonal wind at $60^{\circ} \mathrm{N}$ and $10 \mathrm{hPa}$ becomes easterly during the extended winter (November-March). This date is referred to as the central date. As in Charlton and Polvani (2007), no temperature criterion is employed and final warmings are excluded by requiring that fol- lowing the onset of easterlies the wind must become westerly for at least 10 days prior to the end of April. To prevent counting a single SSW twice, and to avoid biasing the composites, the central dates must be separated by at least 60 days, a value that is larger than that used by Charlton and Polvani. Because observed SSWs occur on average once every $2 \mathrm{yr}$, with years having two SSWs being rare, our longer minimum separation time makes little difference.

Once the SSWs have been identified, composites are generated by averaging together 120-day time series centered about the central date for each SSW. In addition, several metrics similar to the benchmarks proposed by Charlton and Polvani (2007) are used to quantify the magnitudes of the SSWs. These metrics are the areaaveraged polar cap $\left(60^{\circ}-90^{\circ} \mathrm{N}\right)$ temperature anomalies at 10 and $50 \mathrm{hPa}$, averaged \pm 5 days about the central date (denoted $\Delta \bar{T}_{10}$ and $\Delta \bar{T}_{50}$ ), and the area-averaged mid- to high-latitude $\left(40^{\circ}-80^{\circ} \mathrm{N}\right)$ meridional heat flux anomaly for combined zonal wavenumbers 1 and 2 at $100 \mathrm{hPa}$, averaged 20 days before the central date (denoted $\left.\Delta \overline{v^{\prime} T_{100}^{\prime}}\right)$. Anomalies are defined as departures from the daily climatological annual cycle, which is computed from the multiyear 12-month dataset and smoothed using a 90-day low-pass filter. Single sets of climatologies are computed for the REF1 and REF2 simulations.

\section{b. NAM method}

Here, the simplified daily NAM index discussed in Baldwin and Thompson (2009) is used to identify SSWs. The calculation of the NAM index follows exactly from that described in that paper: EOFs are first computed from zonal and monthly mean geopotential anomalies at $10 \mathrm{hPa}$ poleward of $20^{\circ} \mathrm{N}$ for the extended winter (November-March). The daily NAM index, which by construction is dimensionless (i.e., denoting the departure of the zonal mean state from the daily climatology in units of standard deviation), is then computed by projecting daily average geopotential anomalies onto the leading EOF pattern. The daily average climatologies are computed as before using low-pass-filtered ensemble averages. In section $4 \mathrm{~b}$, where SSWs in the past and future are compared, a single EOF is computed using combined past and future geopotential anomalies, with past anomalies computed from the past climatology and future anomalies from the future climatology. This is a necessary step that enables the NAM indices to be compared in a consistent fashion because it removes any possible offset in the NAM indices that may occur as a result of climate change. Trends in the NAM indices within the 40-yr time periods are irrelevant because, to first order, climate change will impart a constant linear 


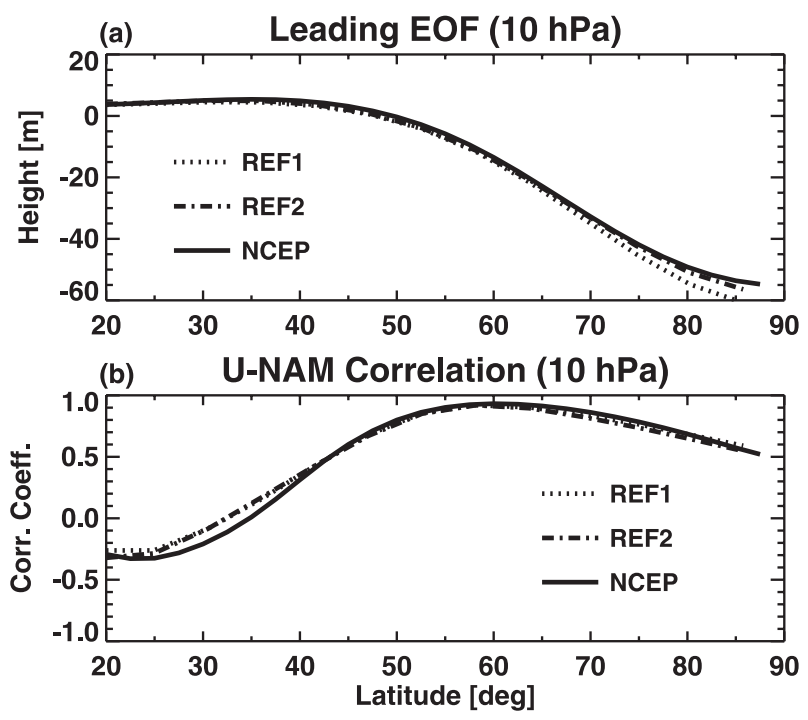

FIG. 1. (a) Leading EOF computed from zonal and monthly mean geopotential height anomalies at $10 \mathrm{hPa}$ from November to March (1960-2004). (b) Correlation coefficient between the daily NAM index at $10 \mathrm{hPa}$ and the daily zonal mean zonal wind at $60^{\circ} \mathrm{N}$, $10 \mathrm{hPa}$ for DJF (1960-2004).

trend that cancels out when the past and future periods are compared. It turns out that the EOF that is computed using the combined anomalies is nearly identical to that using only the past (or future) anomalies. Consequently, the resulting NAM indices are nearly the same as those computed using separate EOFs.

Figure 1a shows the spatial structure of the leading EOF for the two sets of CMAM ensembles and for NCEP, all for the recent past (1960-2004). As can be seen, the agreement between CMAM and NCEP is very good. Because geostrophy provides a strong dynamical constraint relating geopotential and zonal wind, a high correlation exists between the daily NAM index and the zonal mean zonal wind. Figure $1 \mathrm{~b}$ shows the corresponding correlation coefficient between these two variables as a function of latitude for the CMAM ensemble averages and NCEP for December-February (DJF) for the recent past. All three curves are very similar, exhibiting high correlations poleward of $\sim 50^{\circ} \mathrm{N}$ that peak at $\sim 0.95$ at $60^{\circ} \mathrm{N}$.

A SSW is defined to occur when the NAM index first drops below -2.5 (the central date), a threshold chosen to yield the same number of SSWs as the standard method when using NCEP data for the recent past. As with the standard method, SSWs must be separated by at least 60 days, and only extended winter months (November-March) are used. Figure 2 shows SSWs (filled circles) computed using the two methods for a single extended winter from NCEP. The two methods yield identical results for this particular year, although

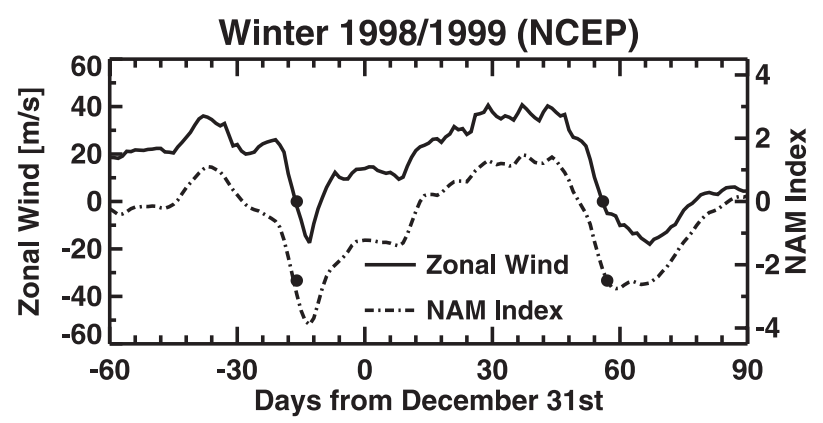

FIG. 2. NAM index at $10 \mathrm{hPa}$ and zonal mean zonal wind at $60^{\circ} \mathrm{N}$, $10 \mathrm{hPa}$ for NCEP for the extended winter of 1998/99. Solid circles denote SSWs computed using the standard method (first occurrence of easterlies) and the NAM method (NAM index first drops below -2.5). Days range from 1 Nov to 31 Mar.

other years can be different. Composites and benchmarks are computed as before.

\section{Results}

\section{a. SSWs in the recent past}

To build confidence in CMAM's ability to simulate future changes in SSWs, we first validate the SSWs for the present day. Because our future predictions employ model SSTs, it is also important to quantify their possible impact on SSWs; this is done by comparing the REF1 and REF2 simulations. Here, we examine 44 extended winters (November-March) in the recent past (19602004). Note that the first $10 \mathrm{yr}$ of these simulations (i.e., prior to 1960) are considered spinup and are thereby discarded. For reference, Table 1 lists the number of SSWs computed using the two methods for the past (and future) time periods.

For a model to reproduce the observed statistics of SSWs, it must have a realistic climatological zonal mean state. This follows from linear theory, whereby the strength and curvature of the zonal mean zonal wind are crucial for determining the propagation of planetary waves into the stratosphere. A good demonstration of this is found in Charlton et al. (2007), where models with unrealistically strong climatological zonal mean westerlies in the lower and middle stratosphere have far too few SSWs. Similarly, models with overly weak climatological westerlies tend to have too many SSWs. Figure 3 shows the climatological zonal mean zonal winds for DJF for the REF1 and REF2 ensemble averages and for NCEP. The agreement between CMAM and NCEP is very good overall, but with CMAM slightly underestimating the strength of the westerlies in the highlatitude upper troposphere and lower stratosphere at $\sim 200 \mathrm{hPa}$ and overestimating the strength of the subtropical jet by $\sim 5 \mathrm{~m} \mathrm{~s}^{-1}$. The seasonal cycle at 
TABLE 1. Number of SSWs computed using the standard and NAM methods for NCEP and the two REF1 simulations for the past (1960-2004), and for the three REF2 simulations for both the past and the future (2055-99).

\begin{tabular}{lcccc}
\hline \hline $\begin{array}{c}\text { Method } \\
\text { Period }\end{array}$ & $\begin{array}{c}\text { Standard } \\
\text { 1960-2004 }\end{array}$ & $\begin{array}{c}\text { NAM } \\
\text { 1960-2004 }\end{array}$ & $\begin{array}{c}\text { Standard } \\
\text { 2055-99 }\end{array}$ & $\begin{array}{c}\text { NAM } \\
\text { 2055-99 }\end{array}$ \\
\hline NCEP & 25 & 25 & - & - \\
REF1-A & 28 & 23 & - & - \\
REF1-B & 26 & 19 & - & - \\
REF2-A & 22 & 25 & 39 & 22 \\
REF2-B & 26 & 21 & 37 & 28 \\
REF2-C & 19 & 22 & 35 & 20 \\
\hline
\end{tabular}

$10 \mathrm{hPa}$ is shown in Fig. 4 (left panels). Again, very good overall agreement is seen between the two CMAM ensemble averages and NCEP.

In addition to needing a realistic climatological zonal mean state, a model also needs realistic planetary wave forcing if the simulated SSWs are to compare favorably with observations. The meridional heat flux at $100 \mathrm{hPa}$ is generally regarded as the key metric for resolved wave forcing of the winter stratosphere. As shown by Charlton et al. (2007), models with a weak climatological heat flux also have too few SSWs. To emphasize the planetary wave component of the heat flux, which is, of course, most relevant to SSWs, the heat flux should be filtered in longitude. The corresponding CMAM results for zonal wavenumbers 1 and 2, which are shown in Fig. 4 (right panels), are in excellent agreement with NCEP.

We conclude from this comparison that CMAM is able to reasonably well simulate the wintertime climatological zonal mean state and planetary wave forcing in the Northern Hemisphere. Moreover, no significant differences between the REF1 and REF2 simulations are found, indicating that, with respect to the climatologies, the use of model SSTs is not an issue. We turn now to an examination of the SSWs.

Figure 5 shows SSW composites of zonal wind, temperature anomalies, and meridional heat flux anomalies computed using the standard method. Day zero (the central date) is when the zonal wind becomes easterly. The composite SSW is characterized by a rapid deceleration of the $10-\mathrm{hPa}$ westerlies (Fig. 5a), commencing about 20 days before day 0 , with a subsequent slow return to much weaker westerlies. The agreement between CMAM and NCEP is excellent. Concurrent with the zonal wind deceleration is a rapid increase up to day 0 of the $10-\mathrm{hPa}$ temperature anomalies and a rapid decrease to negative values thereafter (Fig. 5b). Although the peak temperatures for CMAM are somewhat higher than those for NCEP, it should be noted that $10 \mathrm{hPa}$ is near the lid of the NCEP model, which may account for some of this difference. Supporting evidence for this is seen in

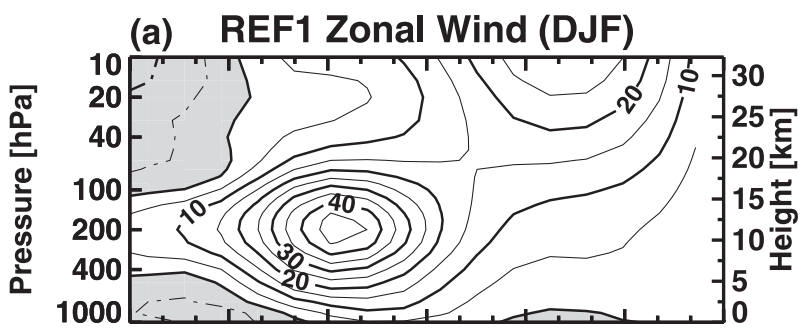

(b) REF2 Zonal Wind (DJF)

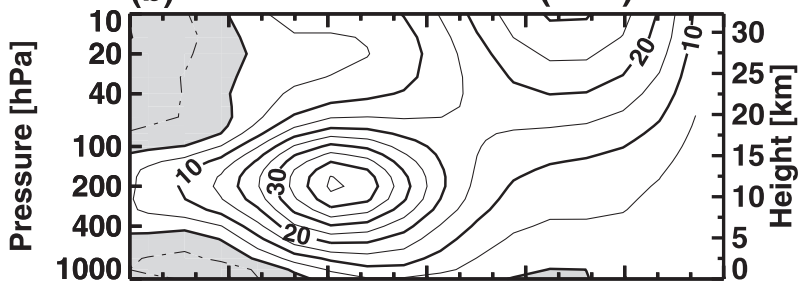

(c) NCEP Zonal Wind (DJF)

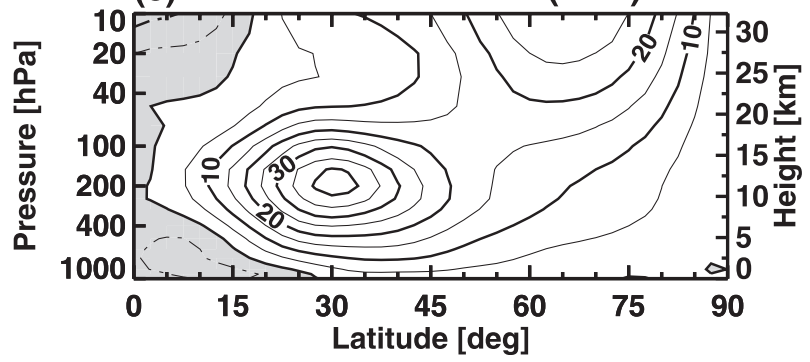

FIG. 3. Zonal mean zonal wind $\left(\mathrm{m} \mathrm{s}^{-1}\right)$ for DJF (1960-2004) for (a) REF1, (b) REF2, and (c) NCEP. Easterlies are shaded. The log-pressure height, computed using a scale height of $7 \mathrm{~km}$, is given on the right axis. Ensemble averages for REF1 and REF2 are shown.

Figs. 5c,d, which show better agreement with NCEP for temperature anomalies at 50 and $100 \mathrm{hPa}$. Note also the asymmetry of the 50 - and $100-\mathrm{hPa}$ temperature anomalies about the central date, with a much slower decay after day 0 than at $10 \mathrm{hPa}$. This is a consequence of the longer thermal damping time scales in the lower stratosphere. Again, excellent agreement between CMAM and NCEP is seen. Figures $5 \mathrm{e}$,f show $100-\mathrm{hPa}$ heat flux anomalies for zonal wavenumbers 1 and 2, respectively. The wavenumber- 1 heat flux exhibits a gradual increase up to day 0 and a rapid decrease to negative values afterward, with the observed behavior well reproduced by CMAM. The wavenumber-2 heat flux is much weaker than that of wavenumber 1 but still exhibits an increase shortly before day 0 ; the ripples on either side of the central date are not significant.

Composites generated using the NAM method are presented in Fig. 6. The top panel shows the $10-\mathrm{hPa}$ NAM index. As before, there is very good overall agreement between CMAM and NCEP, with both showing a rapid decrease before day 0 and a gradual 
(a) REF1 Zonal Wind (10 hPa)

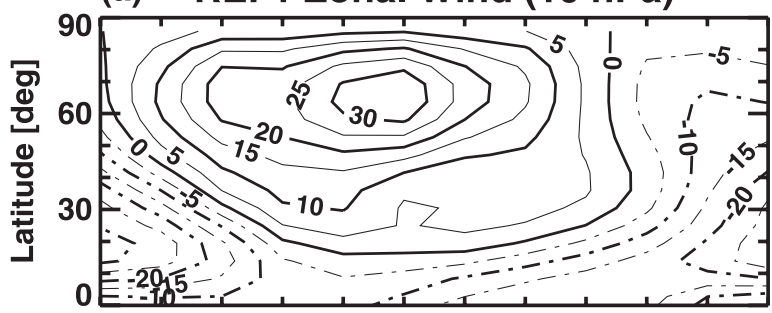

(c) REF2 Zonal Wind (10 $\mathrm{hPa})$

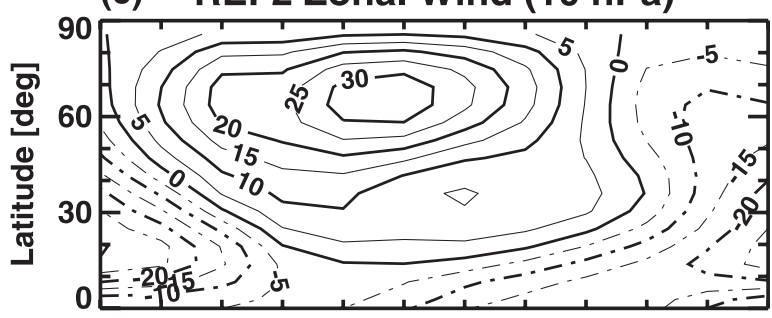

(e) NCEP Zonal Wind (10 $\mathrm{hPa})$

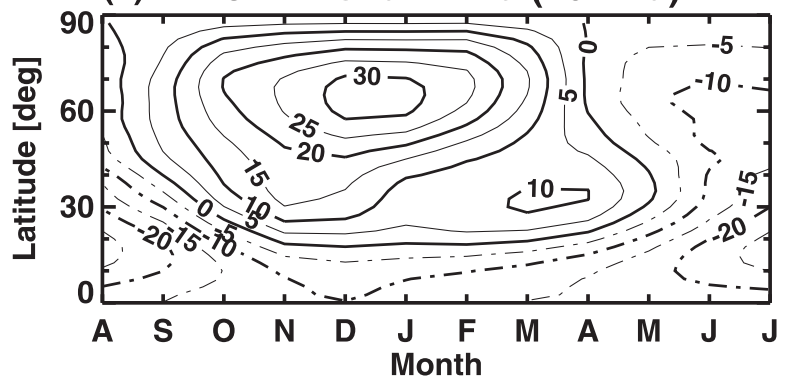

(b) REF1 Heat Flux $(100 \mathrm{hPa})$

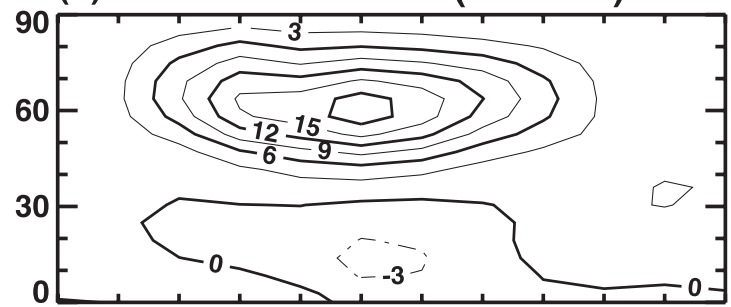

(d) REF2 Heat Flux (100 hPa)

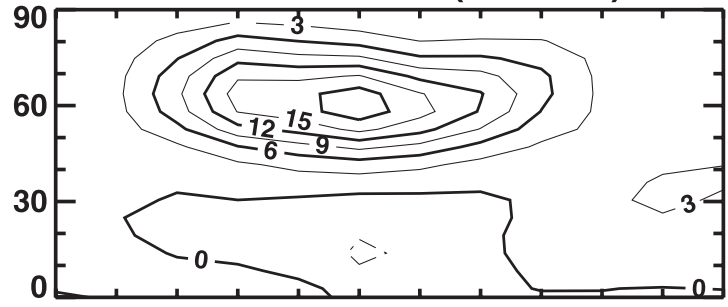

(f) NCEP Heat Flux $(100 \mathrm{hPa})$

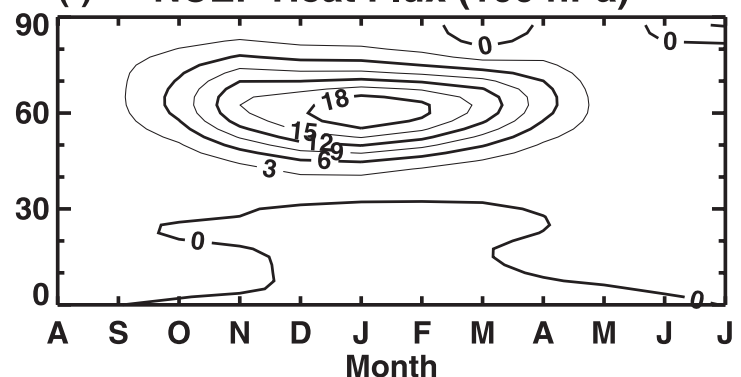

FIG. 4. Monthly and zonal mean zonal wind $\left(\mathrm{m} \mathrm{s}^{-1}\right.$ ) at $10 \mathrm{hPa}$ for (a) REF1, (c) REF2, and (e) NCEP. Monthly mean meridional heat flux for zonal wavenumbers 1 and $2\left(\mathrm{~K} \mathrm{~m} \mathrm{~s}^{-1}\right)$ at $100 \mathrm{hPa}$ for (b) REF1, (d) REF2, and (f) NCEP. Months range from August to July. Ensemble averages for REF1 and REF2 are shown.

increase thereafter. Unlike the zonal wind composite (Fig. 5a), the NAM index composite is constructed from anomalies, and so does not contain the signal of the seasonal cycle; consequently, it asymptotes to the same value on either side of day 0 . Figure $6 \mathrm{~b}$ shows the zonal wind composite constructed using the NAM method. A comparison of Figs. $5 \mathrm{a}$ and $6 \mathrm{~b}$ indicates that the two methods yield very similar results.

A statistical analysis of the SSW benchmarks is given in Table 2, which lists mean values, as well as the $t$ statistic and the corresponding significance levels for the differences of the means. Because the true means are assumed to be the same (the null hypothesis), large significance levels indicate that we have no basis for rejecting the null hypothesis. Overall, the two methods yield qualitatively similar results, but with the NAM method having somewhat larger temperature and heat flux amplitudes. The large significance levels for both frequency and heat flux indicate that the two sets of CMAM simulations are statistically indistinguishable from NCEP and from each other. Charlton et al. (2007) found that most of the models they examined produced fewer SSWs than that observed; our results show that this is not the case for CMAM. Regarding the temperature amplitudes, CMAM exhibits larger values than NCEP at both 10 and $50 \mathrm{hPa}$, with the differences being generally highly statistically significant.

Figures 7a,b show the monthly distributions of SSW frequency computed using the two methods. To get a sense of the variability about the ensemble mean, histograms for the individual ensemble members for the REF1 and REF2 simulations are displayed. CMAM reasonably well reproduces the observed frequency distribution, which peaks in February. This should be contrasted to the finding of Charlton et al. (2007) that none of the models they examined were able to reproduce the observed monthly variation of SSWs, with some biased to early winter and others to late winter. The NAM method, however, tends to have fewer SSWs in late winter (February and March) and more in midwinter.

Figures $7 \mathrm{c}-\mathrm{f}$ show the corresponding monthly histograms for the SSW benchmarks. Aside from the high 
(a) Zonal Wind (10 $\mathrm{hPa})$
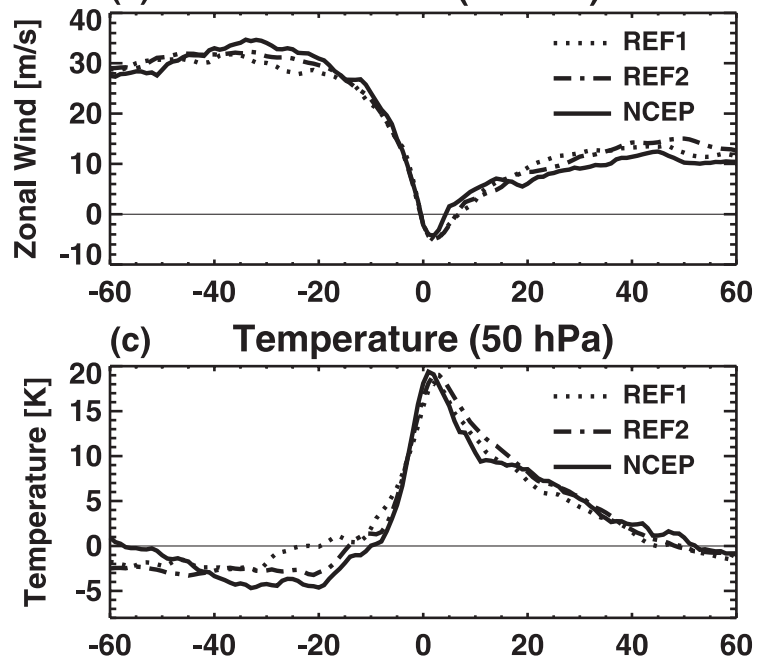

(e) Wave 1 Heat Flux $(100 \mathrm{hPa})$

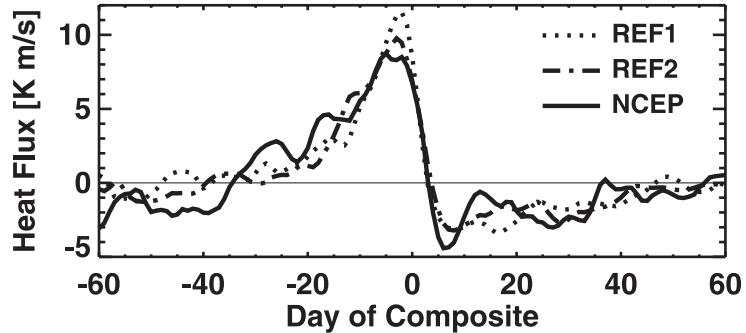

(b) Temperature $(10 \mathrm{hPa})$

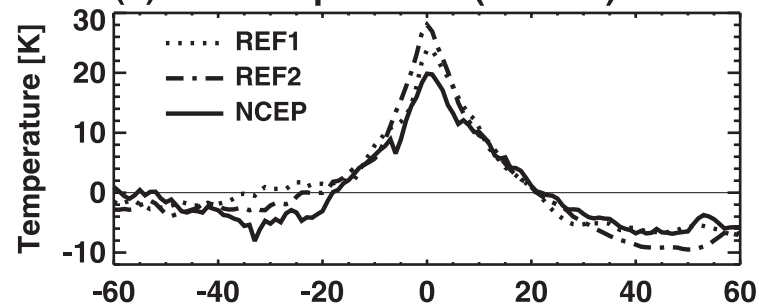

(d) Temperature $(100 \mathrm{hPa})$

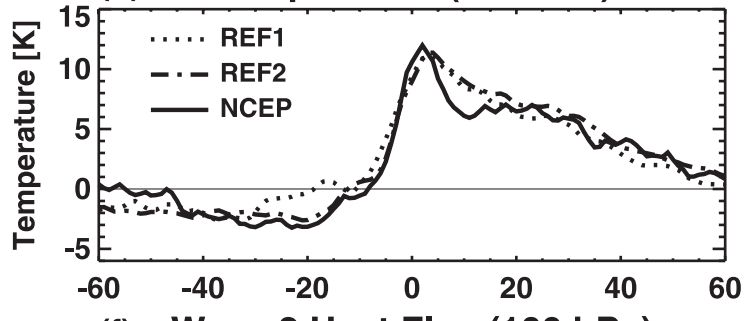

(f) Wave 2 Heat Flux $(100 \mathrm{hPa})$

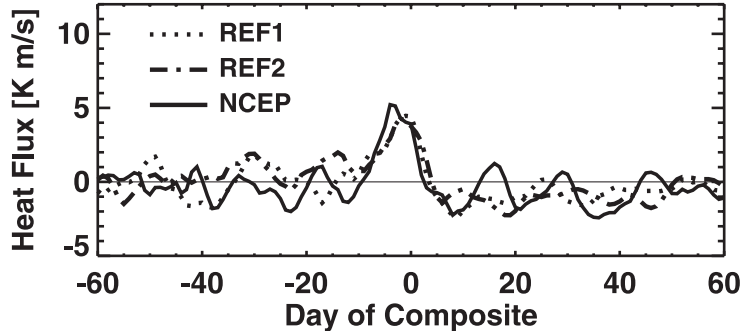

FIG. 5. Composite SSW for 1960-2004 computed using the standard method: (a) zonal mean zonal wind at $60^{\circ} \mathrm{N}, 10 \mathrm{hPa}$; zonal mean temperature anomalies at $90^{\circ} \mathrm{N}$, (b) $10 \mathrm{hPa}$, (c) $50 \mathrm{hPa}$, and (d) $100 \mathrm{hPa}$; and meridional heat flux anomalies at $100 \mathrm{hPa}$ area-averaged from $40^{\circ}$ to $80^{\circ} \mathrm{N}$ for zonal wavenumbers (e) 1 and (f) 2 . Day zero is when the zonal wind is first easterly. The thin straight lines are shown to help guide the eye.

temperature bias mentioned earlier, CMAM reproduces the observed seasonal variation of $\Delta \bar{T}_{10}$ quite well. Likewise, $\Delta \overline{v^{\prime} T_{100}^{\prime}}$ is also reasonable. The benchmarks computed using the NAM method (right panels) tend to be larger in late winter, in conjunction with the fewer number of SSWs noted above (i.e., the NAM method selects the stronger SSWs during this period).

Summarizing the results from this section, we conclude that CMAM is able to reasonably well reproduce the observed characteristics of SSWs. Moreover, no significant difference between the REF1 and REF2 simulations is found, indicating that the use of model SSTs in the REF2 simulations has no detrimental impact on SSWs. The two methods for identifying SSWs also yield similar results, but with a tendency for fewer SSWs in late winter for the NAM method.

\section{b. SSWs in the future}

Figure 8 shows time series of the SSW frequency and temperature amplitude $\Delta \bar{T}_{10}$ for the three REF2 simulations (colored symbols) and the corresponding en- semble averages (filled circles) computed over 10-yr intervals. The red lines are the linear fits through the solid circles. Unlike the other results, the climatologies used here to compute the anomalies are generated by fitting the 140-yr time series to a trend and offset for each day of the year. This yields daily climatologies that depend linearly on year. The results using the standard method (left panels) exhibit a clear secular increase in SSW frequency (Fig. 8a), like the finding of CharltonPerez et al. (2008). This occurs in conjunction with a clear secular decrease in $\Delta \bar{T}_{10}$ (Fig. 8c). The linear nature of these trends suggests that climate change is responsible. The right panels show results for the NAM method. The most striking difference is the complete absence of a positive trend in the frequency of occurrence of SSWs. Furthermore, the negative trend in $\Delta \bar{T}_{10}$ is weaker than that in Fig. 8c.

Figure 8 also indicates that there is considerable variability on multidecadal time scales, especially for individual simulations: different ensemble members can give opposite trends over several decades (cf. Butchart et al. 2000). This highlights the need to perform an ensemble of 
(a) NAM Index (10 hPa)

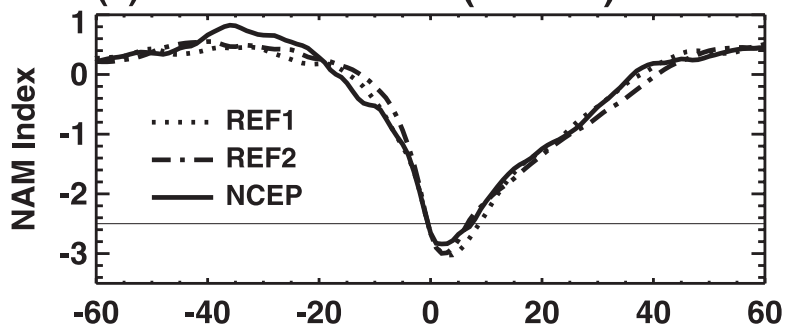

(b) Zonal Wind $\left(60^{\circ} \mathrm{N} \& 10 \mathrm{hPa}\right)$

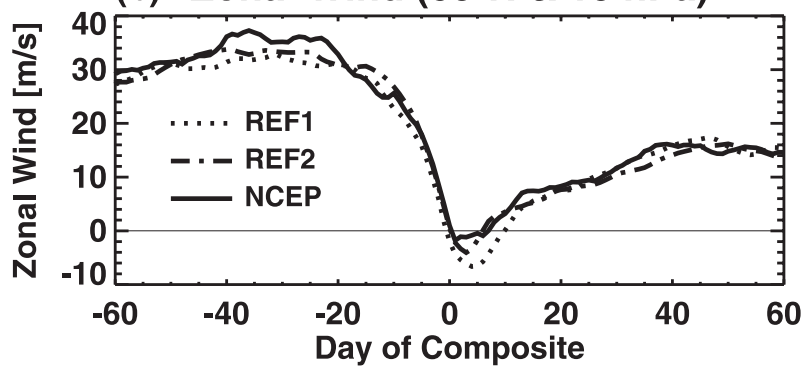

FIG. 6. Composite SSW for 1960-2004 computed using the NAM method: (a) NAM index at $10 \mathrm{hPa}$, and (b) zonal mean zonal wind at $60^{\circ} \mathrm{N}, 10 \mathrm{hPa}$. Day zero is when the NAM index first drops below -2.5 (the thin straight line in the top panel)

long simulations in order to reliably detect the effects of climate change on Arctic wintertime variability.

In the remainder of this section we focus on the statistical nature of the changes in SSWs by comparing 44 extended winters in the future (2055-99) and the past (1960-2004) from the REF2 simulations. The numbers of SSWs computed for these two periods are listed in Table 1.

Histograms of the past and future SSW benchmarks computed using the standard method are shown in Fig. 9 (left panels). The largest future increase in frequency is found in late winter (February and March), as in Charlton-Perez et al. (2008). No marked change in the seasonal distribution of either of the two benchmarks is seen. The statistics of the future changes, which are listed in Table 3 (top four rows), indicate a $\sim 60 \%$ increase in frequency, $\sim 25 \%$ decrease in $\Delta \bar{T}_{10}$ and $\Delta \bar{T}_{50}$, and $\sim 15 \%$ decrease in $\Delta \overline{v^{\prime} T_{100}^{\prime}}$. The very small significance levels, with the exception of that for the heat flux, indicate a high level of confidence in rejecting the null hypothesis (i.e., that the past and future means are the same).

The corresponding results using the NAM method are presented in the right panels of Fig. 9 and in Table 3 (bottom four rows). As was seen in Fig. 8b, no future increase in the frequency of SSWs occurs. Furthermore, no statistically significant future changes in either $\Delta \overline{v^{\prime} T_{100}^{\prime}}$ or $\Delta \bar{T}_{50}$ are found, although the $\sim 10 \%$ future decrease in $\Delta \bar{T}_{10}$ is statistically significant.

The above findings regarding the NAM method are confirmed using an entirely different calculation shown in Figs. 10 and 11, which show standard deviations of the anomalous daily zonal mean temperature $\left(\sigma_{\bar{T}}\right)$ and meridional heat flux at $100 \mathrm{hPa}\left(\sigma_{v^{\prime} T^{\prime}}\right)$ for the past and future. Because anomalies of all sizes are included here, the values are smaller than the SSWs listed in Table 3. Nevertheless, the spatial structure of $\sigma_{\bar{T}}$, with maximum values in the polar middle stratosphere, is characteristic of that of SSWs. In agreement with the NAM results, $\sigma_{\bar{T}}$ at $10 \mathrm{hPa}$ is somewhat reduced in the future (Fig. 10b), but lower down at $50 \mathrm{hPa}$ it exhibits little change. Likewise, $\sigma_{v^{\prime} T^{\prime}}$ is also practically unchanged (Fig. 11), despite the future increase in the climatological mean value (not shown) that drives the increase in the strength of the BDC in these simulations (McLandress and Shepherd 2009).

To understand why the standard method and NAM method produce such different results for the future changes in SSWs, the differences in the two methods must be borne in mind. As discussed earlier, the standard

TABLE 2. Statistics of SSW benchmarks for the past (1960-2004) computed using the two methods. Columns 3-5 list mean values; columns 6-8 list the $t$ statistic and corresponding significance levels for the differences between REF1 and NCEP, REF2 and NCEP, and REF1 and REF2, respectively. Units are $\mathrm{yr}^{-1}$ for frequency, $\mathrm{K}$ for $\Delta \bar{T}_{10}$ and $\Delta \bar{T}_{50}$, and $\mathrm{K} \mathrm{m} \mathrm{s}{ }^{-1}$ for $\Delta \overline{v^{\prime} T_{100}^{\prime}}$. The $t$ statistic is computed assuming independent and randomly distributed data. Data for the two REF1 simulations are combined when computing the statistics likewise for the three REF2 simulations. Refer to section 3a for the definitions of $\Delta \bar{T}_{10}, \Delta \bar{T}_{50}$, and $\Delta{\overline{v^{\prime}}}_{100}^{\prime}$.

\begin{tabular}{lccccccc}
\hline \hline & Method & $\begin{array}{c}\text { NCEP } \\
\text { Mean }\end{array}$ & $\begin{array}{c}\text { REF1 } \\
\text { Mean }\end{array}$ & $\begin{array}{c}\text { REF2 } \\
\text { Mean }\end{array}$ & $\begin{array}{c}\text { REF1 - NCEP } \\
|t| \\
\text { (significance level) }\end{array}$ & $\begin{array}{c}\text { REF2 - NCEP } \\
|t| \text { (significance level) }\end{array}$ & $\begin{array}{c}\text { REF1 - REF2 } \\
|t| \\
(\text { significance level) }\end{array}$ \\
\hline Frequency & Standard & 0.56 & 0.63 & 0.52 & $0.6(57 \%)$ & $0.3(74 \%)$ & $1.4(16 \%)$ \\
$\Delta \bar{T}_{10}$ & - & 10.6 & 14.2 & 16.5 & $2.4(2 \%)$ & $4.0(0.02 \%)$ & $1.7(9 \%)$ \\
$\Delta \bar{T}_{50}$ & - & 6.6 & 8.1 & 8.3 & $1.9(6 \%)$ & $2.2(4 \%)$ & $0.4(71 \%)$ \\
$\Delta \bar{v}^{\prime} T_{100}^{\prime}$ & - & 7.3 & 7.1 & 7.7 & $0.2(82 \%)$ & $0.3(77 \%)$ & $0.7(50 \%)$ \\
Frequency & NAM & 0.56 & 0.49 & 0.52 & $0.7(49 \%)$ & $0.4(69 \%)$ & $0.4(67 \%)$ \\
$\Delta \bar{T}_{10}$ & - & 12.5 & 17.7 & 18.1 & $3.8(0.03 \%)$ & $4.5(0.004 \%)$ & $0.4(72 \%)$ \\
$\Delta \bar{T}_{50}$ & - & 7.4 & 9.6 & 8.5 & $4.8(0.001 \%)$ & $2.6(1 \%)$ & $3.0(0.3 \%)$ \\
$\Delta \bar{v}^{\prime} T_{100}^{\prime}$ & - & 8.6 & 8.9 & 8.6 & $0.3(79 \%)$ & $0.1(93 \%)$ & $0.4(68 \%)$ \\
\hline
\end{tabular}


(a) Frequency (Standard Method)

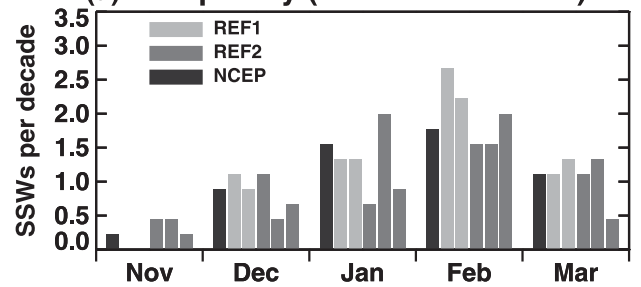

(c)

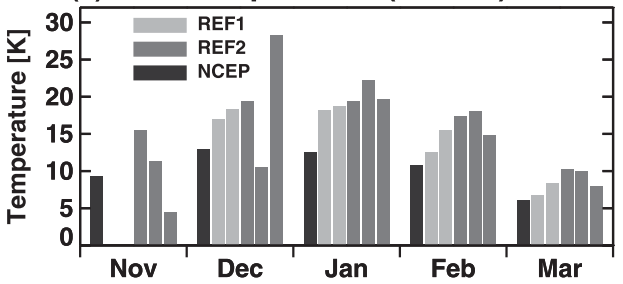

(e)

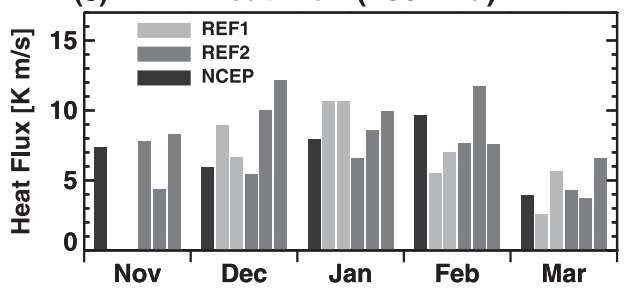

(b) Frequency (NAM Method)

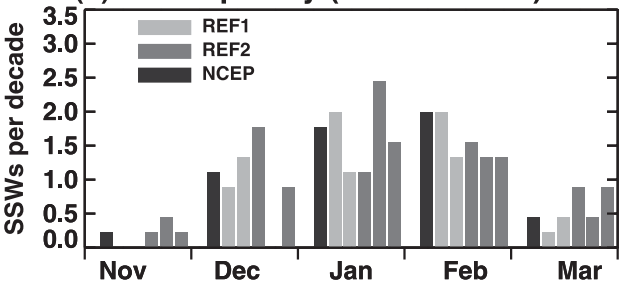

(d) Temperature $(10 \mathrm{hPa})$

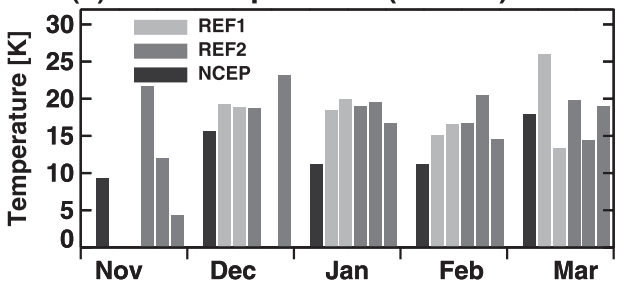

(f)

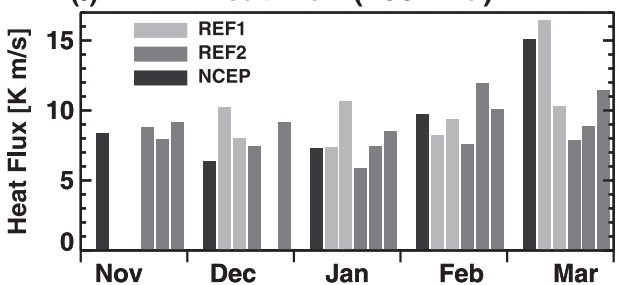

FIG. 7. Histograms of monthly variations of the SSW benchmarks for 1960-2004 computed using the (left) standard and (right) NAM methods: (a),(b) frequency, (c),(d) $\Delta \bar{T}_{10}$, and (e),(f) $\Delta{\overline{v^{\prime} T_{100}^{\prime}}}_{\text {for zonal }}$ wavenumbers 1 and 2. Results are shown for NCEP (dark gray bar), the REF1 ensemble members (two light gray bars), and the REF2 ensemble members (three medium gray bars). Refer to section 3a for the definitions of $\Delta \bar{T}_{10}$ and $\Delta \overline{v^{\prime} T_{100}^{\prime}}$.

method uses an absolute criterion to identify SSWs based on the zonal mean zonal wind. If the climatological mean wind changes in the future, the likelihood for a SSW to occur, from a purely statistical stand point, will also change: a decrease in mean westerlies at $60^{\circ} \mathrm{N}$ and $10 \mathrm{hPa}$ would make it easier for a SSW to occur, and an increase would make it more difficult. Conversely, the NAM method uses a relative criterion based on anomalies, and so it is unaffected by future changes in the climatology.

To verify this, we examine the future changes in the zonal mean zonal wind at $10 \mathrm{hPa}$, which are shown in Fig. 12. Climate change has resulted in a weakening of the westerlies at high latitudes, which peaks at $\sim 8 \mathrm{~m} \mathrm{~s}^{-1}$ in February. This coincides precisely with the largest future increase in the frequency of SSWs computed using the standard method (Fig. 9a). Thus, as climate change reduces the stratospheric westerlies at high latitudes in late winter in these simulations, weaker temperature and heat flux anomalies are needed to bring about a wind reversal, which explains the future decreases in $\Delta \bar{T}_{10}, \Delta \bar{T}_{50}$ and $\Delta \overline{v^{\prime} T_{100}^{\prime}}$ that were noted earlier in regards to the standard method.
The above argument implicitly assumes that SSWs are not responsible for the future changes in the climatological mean winds. Evidence for this is found in McLandress and Shepherd (2009), who show that the reduction in zonal mean zonal winds in the winter lower stratosphere is a consequence of increased downwelling resulting from an increase in stationary (i.e., monthly mean) planetary wave drag. However, because monthly averaged planetary wave drag also includes amplifying and decaying disturbances (which include SSWs), one cannot completely rule out the role of SSWs in altering the climatological state. To properly address this issue, one must therefore isolate the effects of the SSWs.

Because of the very long radiative time scales in the lower stratosphere, SSWs can affect the winter circulation for weeks following the breakdown of the vortex, as can be seen by the slow decay of the composite temperature anomalies in Fig. 5. Thus, subdividing individual winters into time periods with and without SSWs is problematic. One way to isolate the effects of SSWs in a physically meaningful way, though, is by examining winters with and without SSWs. Here, we consider only midwinter (DJF) changes, and we define a winter with SSWs as one 
(a) Frequency (Standard Method)

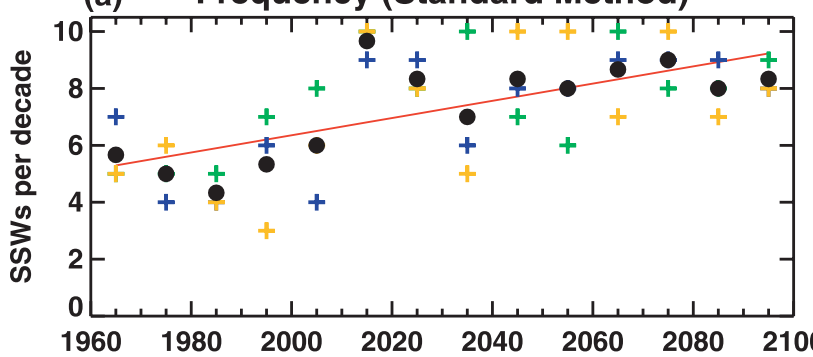

(c)

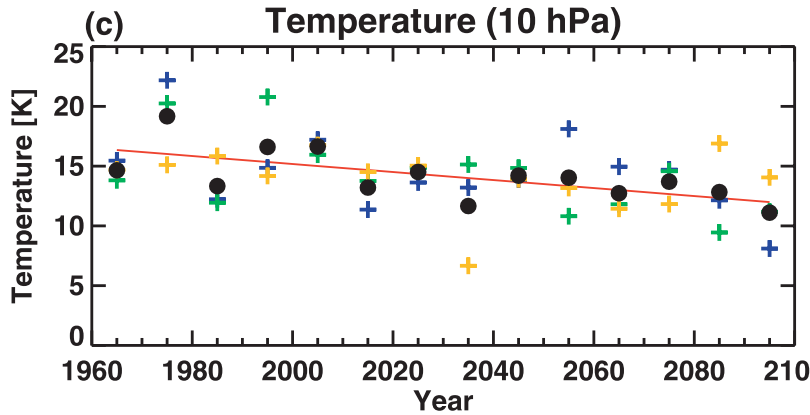

(b)

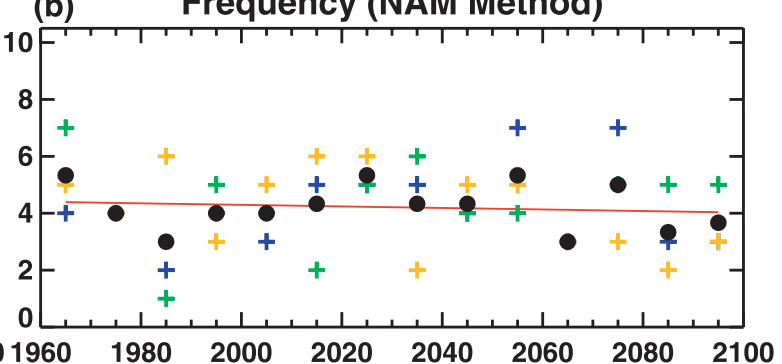

(d) Temperature $(10 \mathrm{hPa})$

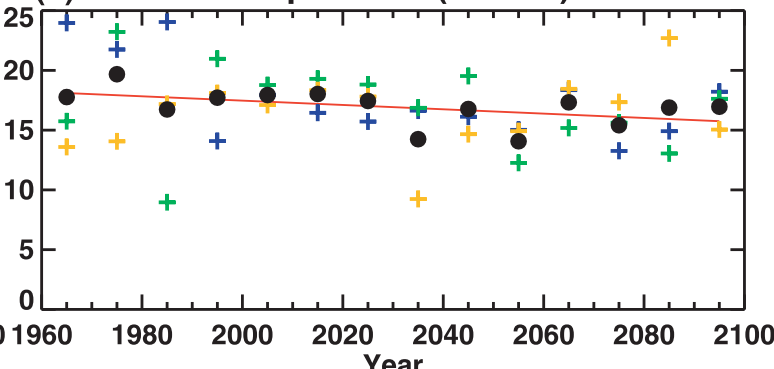

FIG. 8. Time series of (a),(b) SSW frequency and (c),(d) $\Delta \bar{T}_{10}$ computed using the (left) standard and (right) NAM methods for the REF2 simulations. The three ensemble members are denoted by the blue, green, and yellow symbols, and the ensemble averages by the solid circles. The red lines are the linear fits through the ensemble averages. Results are computed for 10-yr intervals centered about the position of the plotted symbols.

with SSWs occurring any time from the beginning of November to the end of February. All other years are therefore winters without SSWs.

Figure 13 (top row) shows the zonal mean zonal winds for DJF for the past winters with and without SSWs, and the corresponding differences. Here the standard method for identifying SSWs has been employed. As expected, winters without SSWs have significantly stronger westerlies in the high-latitude stratosphere. The corresponding differences between future and past are shown in Figs. $13 \mathrm{~d}$,e. Poleward of $\sim 50^{\circ} \mathrm{N}$ in the stratosphere, the zonal wind differences are very similar in structure, as is made clearer in Fig. 13f, which shows differences between the two bottom left panels. (Similar results are found when the NAM method is used.) This demonstrates that the reduced mean wind speeds seen in Fig. 12b at high latitudes in late winter are not related to SSWs.

\section{c. Impact of SSWs on the Brewer-Dobson circulation}

Given the importance of wave drag in driving the residual circulation, it is of interest to know what impact SSWs have on the BDC. Because this is not possible with reanalysis data (resulting from the noisy vertical motion fields produced by data assimilation), one must turn to model data. Here, we examine the CMAM data, using only results from the REF2 simulations and employing the same method as before for separating the winters.
Figure 14 shows the area-weighted residual vertical velocity $\bar{w}^{*}$ at $70 \mathrm{hPa}$ for DJF in the recent past for winters both with and without SSWs. These results are obtained using the standard method; the NAM method yields very similar results. The downward motion in the midand high latitudes and the compensatory upward motion between $\sim 40^{\circ} \mathrm{S}$ and $30^{\circ} \mathrm{N}$ is characteristic of the BDC. Winters with SSWs have a stronger BDC, with both increased polar downwelling and increased tropical upwelling. The increased upwelling, in fact, is spread out over a wide latitude range extending well into the Southern Hemisphere. The differences between the two curves, which are of the order of $\sim 10 \%$ at high latitudes, are consistent with the changes in the zonal mean zonal wind seen in Fig. 13c.

Multimodel simulations of stratosphere-resolving general circulation models predict an increase in the strength of the BDC in response to climate change (Butchart et al. 2006). A similar increase has also been found in the CMAM REF2 simulations discussed in McLandress and Shepherd (2009). Figure 15 shows the net (horizontally integrated) downward mass flux in the Northern Hemisphere for winters with and without SSWs using the standard method to identify the SSWs. As in McLandress and Shepherd, the mass flux is computed poleward of the latitudes in the Northern Hemisphere where downwelling commences (see that paper for more details). Consistent with our previous results (Fig. 14), winters with SSWs 
(a) Frequency (Standard Method)

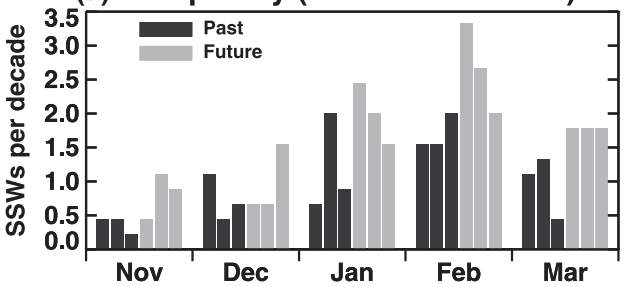

(c)

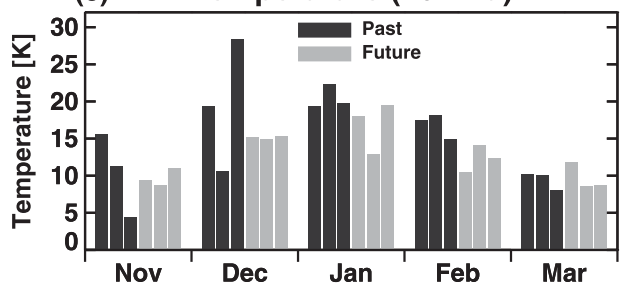

(e)

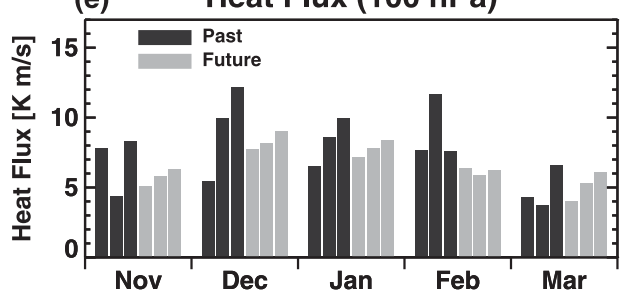

(b) Frequency (NAM Method)

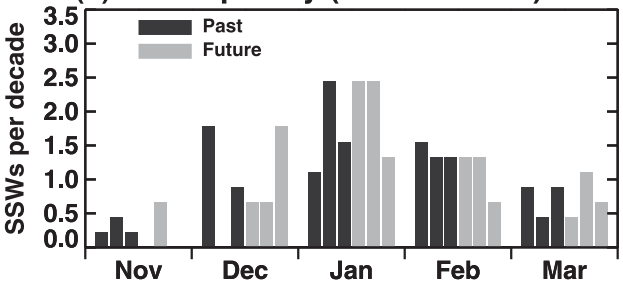

(d)

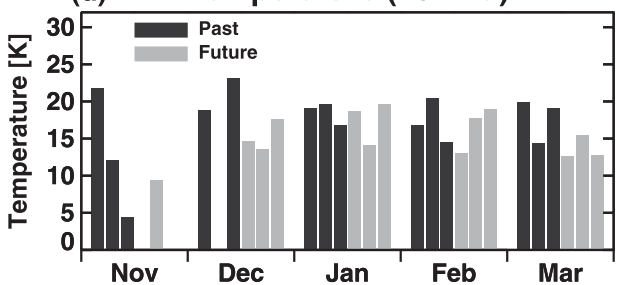

(f)

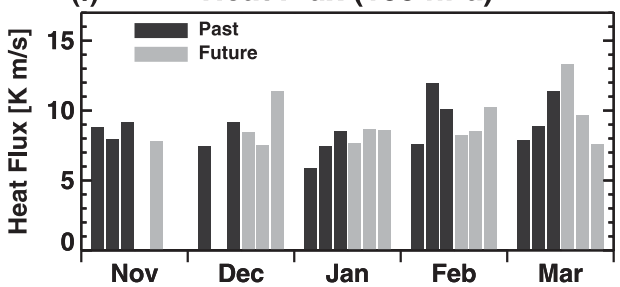

FIG. 9. As in Fig. 7, but for the past (1960-2004) and future (2055-99) for the three REF2 simulations.

have a larger downward mass flux than those without. However, no noticeable change with time in the magnitude of this effect is seen here, indicating that SSWs have no significant impact on the positive trend in the net downward mass flux. This too is consistent with our previous findings that while SSWs increase in frequency in the future when computed using the standard method, their amplitude decreases.

\section{Summary and concluding remarks}

The impact of climate change on the dynamics of Northern Hemisphere major midwinter stratospheric sudden warmings is examined using two sets of transient simulations from the Canadian Middle Atmosphere Model. The first set comprises an ensemble of two simulations from 1950 to 2004 in which observed SSTs are employed. The second is an ensemble of three simulations extending from 1950 to 2100 using model SSTs. Both sets of simulations were used in the CCMVal intercomparison studies of Eyring et al. (2006, 2007). Two methods are used to identify SSWs. The first uses the standard WMO definition, whereby the zonal mean zonal wind at $60^{\circ} \mathrm{N}$ and $10 \mathrm{hPa}$ becomes easterly. The second uses the daily NAM index at $10 \mathrm{hPa}$ computed using an EOF analysis of zonal mean geopotential anomalies (Baldwin and Thompson 2009). There, a SSW is defined to occur when the NAM index drops below a prescribed value determined by requiring that the two methods yield the same number of SSWs when applied to NCEP data. The rationale for using the NAM method is to remove from the identification criterion the dependence of the occurrence of SSWs on the climatological zonal mean. To make a consistent comparison of past and future changes in SSWs, it is important to compute the daily NAM index using a single EOF computed from these two periods.

TABLE 3. Statistics of SSW benchmarks for the past (1960-2004) and future (2055-99) for the REF2 simulations computed using the two methods. Columns 3 and 4 list mean values; column 5 lists the $t$ statistic and corresponding significance levels for the difference between the past and future. Units are $\mathrm{yr}^{-1}$ for frequency, $\mathrm{K}$ for $\Delta \bar{T}_{10}$ and $\Delta \bar{T}_{50}$, and $\mathrm{K} \mathrm{m} \mathrm{s}^{-1}$ for $\Delta \overline{v^{\prime} T_{100}^{\prime}}$.

\begin{tabular}{lcccl}
\hline \hline & Method & $\begin{array}{c}\text { Past } \\
\text { Mean }\end{array}$ & $\begin{array}{c}\text { Future } \\
\text { Mean }\end{array}$ & $\begin{array}{c}\text { Future }- \text { past } \\
|t|\end{array}$ \\
(significance level)
\end{tabular}


(a) Temperature Std Dev (Past)

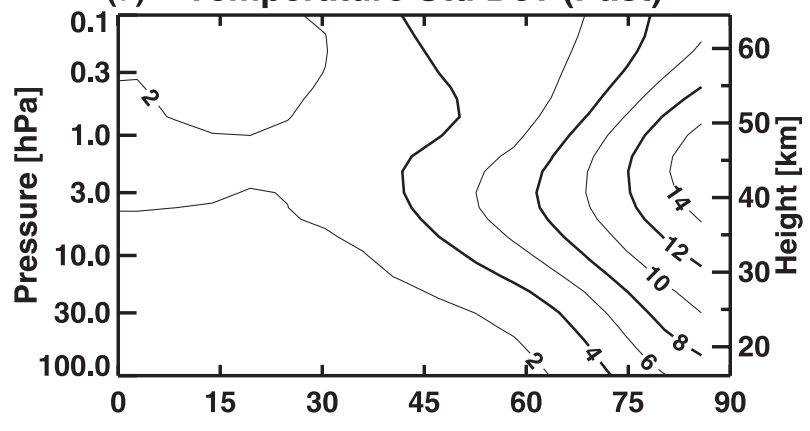

(b) Difference (Future - Past)

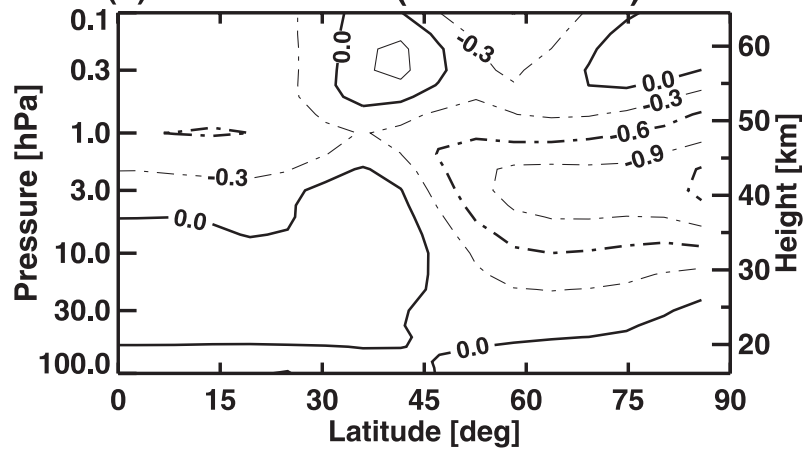

FIG. 10. Standard deviation of daily zonal mean temperature anomalies for November-March for the REF2 simulations for (a) the past (1960-2004) and (b) the difference between the future (2055-99) and the past. Contour intervals are 2 and $0.3 \mathrm{~K}$. Anomalies are computed from the low-pass-filtered ensembleaverage daily climatologies.

The first part of this study involves a comparison of the simulated and observed SSWs for the recent past (1960-2004). The purpose there is twofold-to validate the structure and statistics of the simulated SSWs, and to evaluate the impact on SSWs of using model SSTs. These two steps are crucial if the future changes in SSWs are to be credible. Because the frequency and strength of SSWs are dependent on the underlying zonal mean state (Charlton et al. 2007), the climatological zonal mean zonal winds and planetary wave heat fluxes are first presented; both quantities are in excellent agreement with NCEP. The temporal behavior and magnitudes of composite SSWs constructed from all events are in very good overall agreement with NCEP with regards to zonal wind, temperature, and planetary wave heat flux. A statistical analysis of SSW benchmarks (similar to those discussed in Charlton and Polvani 2007) and of the frequency of occurrence of SSWs shows no significant differences between the simulations and NCEP and between the two sets of simulations. The two methods used to identify SSWs yield similar results, but with the NAM method tending to give fewer and larger amplitude latewinter SSWs than when using the standard method.

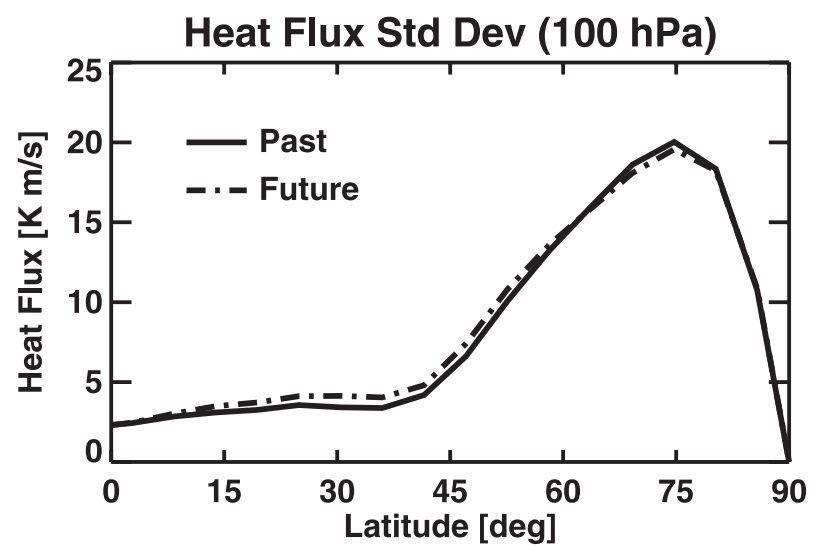

FIG. 11. Standard deviation of daily meridional heat flux anomalies for November-March for the REF2 simulations for the past (1960-2004) and future (2055-99). The heat flux here includes all 32 zonal wavenumbers. Anomalies are computed from the lowpass-filtered ensemble-average daily climatologies.

The good overall agreement in SSW statistics for the REF1 and REF2 simulations indicates that there is no noticeable impact of using model SSTs on the simulated SSWs. This may seem surprising in light of studies showing a link between El Niño-Southern Oscillation (ENSO) and SSWs (e.g., Taguchi and Hartmann 2006), and the difficulty coupled atmosphere-ocean models
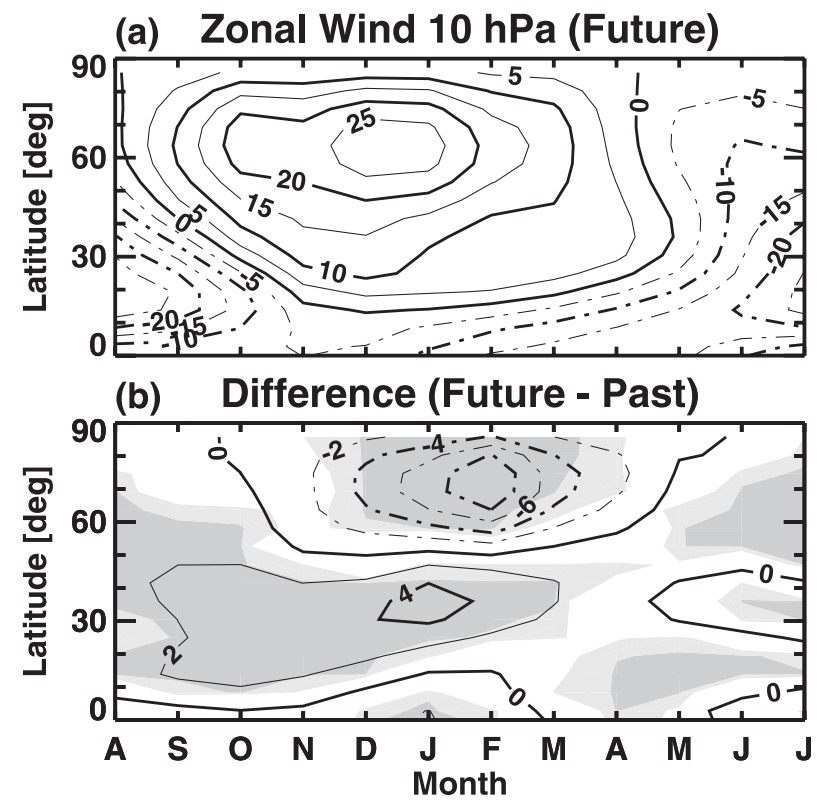

FIG. 12. Monthly and zonal mean zonal wind $\left(\mathrm{m} \mathrm{s}^{-1}\right)$ at $10 \mathrm{hPa}$ for the REF2 ensemble average for (a) the future (2055-99) and (b) the difference between the future and the past (1960-2004). Light and dark shading denote the $90 \%$ and $95 \%$ confidence levels, respectively, computed using the Student's $t$ test. Months range from August to July. 
(a) With SSWs (Past)

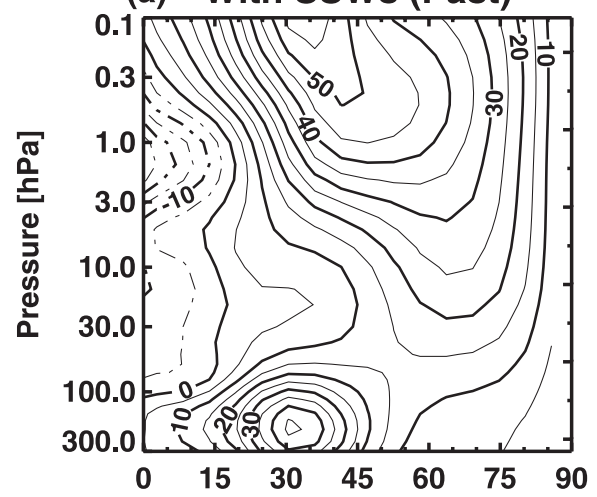

(d) With (Future-Past)

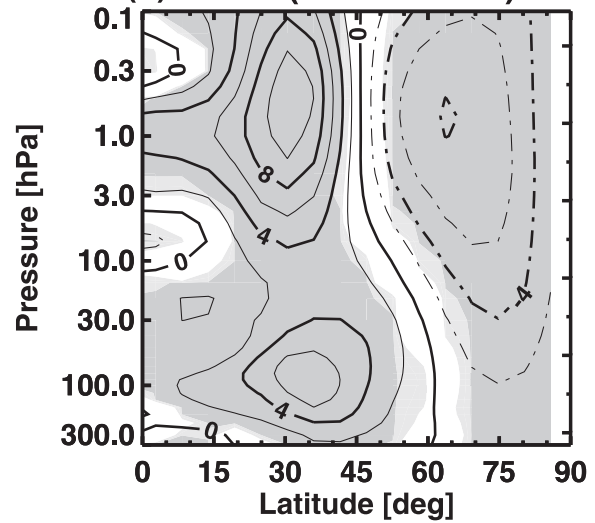

(b) Without SSWs (Past)

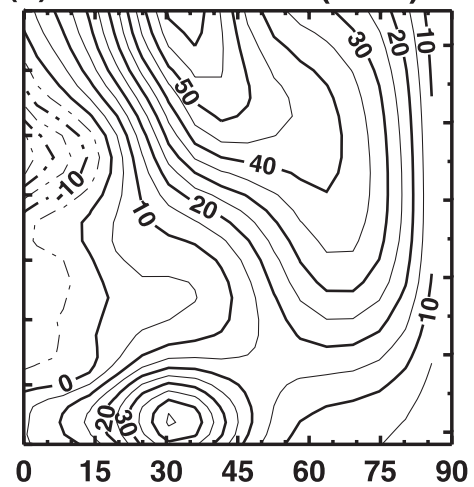

(e)Without (Future-Past)

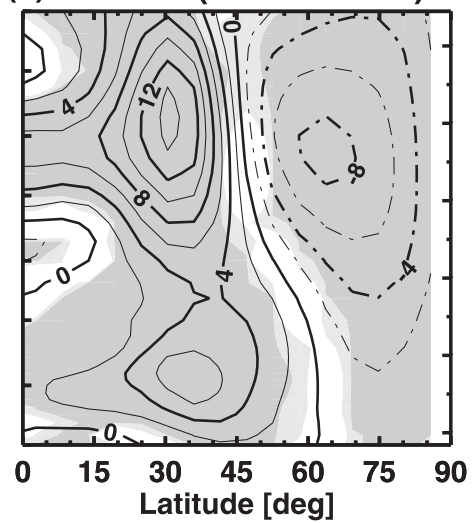

(c) Difference (a-b)

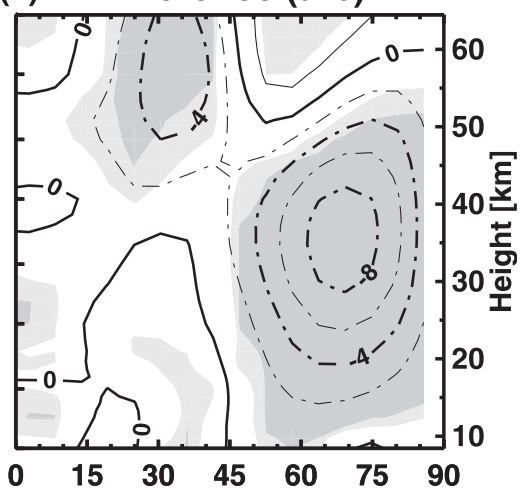

(f) Difference (d-e)

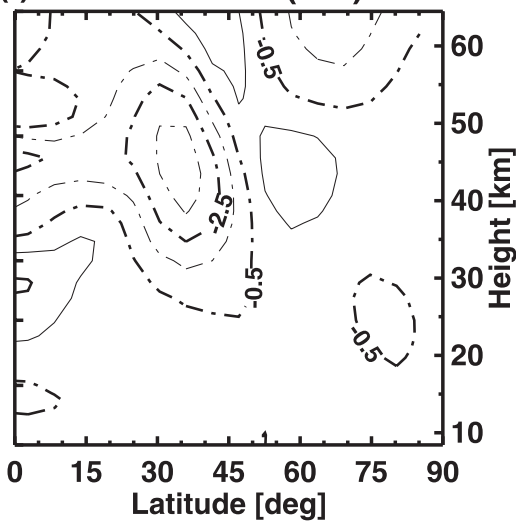

FIG. 13. Zonal mean zonal wind for DJF for the REF2 ensemble average for (top) the past (1960-2004) and (bottom) differences between the future (2055-99) and the past: (a),(d) winters with SSWs, (b),(e) winters without SSWs, (c) difference between (a) and (b), and (f) difference between (d) and (e). Light and dark shading in (c)-(e) denote the $90 \%$ and $95 \%$ confidence levels, respectively, computed using the Student's $t$ test. SSWs are computed using the standard method. Contour intervals are $5 \mathrm{~m} \mathrm{~s}^{-1}$ in (a)-(b), $2 \mathrm{~m} \mathrm{~s}^{-1}$ in (c)-(e), and $1 \mathrm{~m} \mathrm{~s}^{-1}$ in (f).

have in generating realistic ENSOs. However, the frequency of ENSOs (especially large-amplitude events) is so small that their effect on decadal SSW statistics is most likely difficult to detect.

The second part of this study is an examination of future changes in SSWs. Here, only the set of simulations using model SSTs is employed. When the standard method is used to identify SSWs, the frequency of occurrence of SSWs exhibits a secular increase in time, in conjunction with a secular decrease in the $10-\mathrm{hPa}$ polar cap temperature anomaly. This behavior is a strong indication that climate change resulting from steadily increasing greenhouse gases is somehow responsible. Moreover, the secular increase in frequency is similar to that found by Charlton-Perez et al. (2008), indicating that it is not restricted to just one model. A comparison of the past (1960-2004) and future (2055-99) reveals a $\sim 60 \%$ increase in the frequency of SSWs and a $\sim 25 \%$ decrease in their temperature amplitude. When the NAM method is used, however, the frequency of SSWs in the future remains basically unchanged from the past. Consistent with this finding, the variability of the $100-\mathrm{hPa}$ heat flux, which is what drives stratospheric variability, is unchanged in the future, while that of polar temperature is only slightly reduced (and only in the upper stratosphere).

The future increase in SSWs found using the standard method arises because the climatological zonal mean zonal wind at $60^{\circ} \mathrm{N}$ and $10 \mathrm{hPa}$ in these simulations has weakened as a result of climate change (McLandress and Shepherd 2009). A weakened jet means that less wave forcing is required to bring about a wind reversal; that is, the zonal mean winds do not have to decrease as much for the SSW threshold to be reached. This also explains the reduction in the temperature amplitude of the SSWs defined using the standard method. By separating the CMAM data into winters with and without SSWs, the future weakening of the climatological winter westerlies is shown not to be due to SSWs. This provides further indication that the future increase in SSWs found 


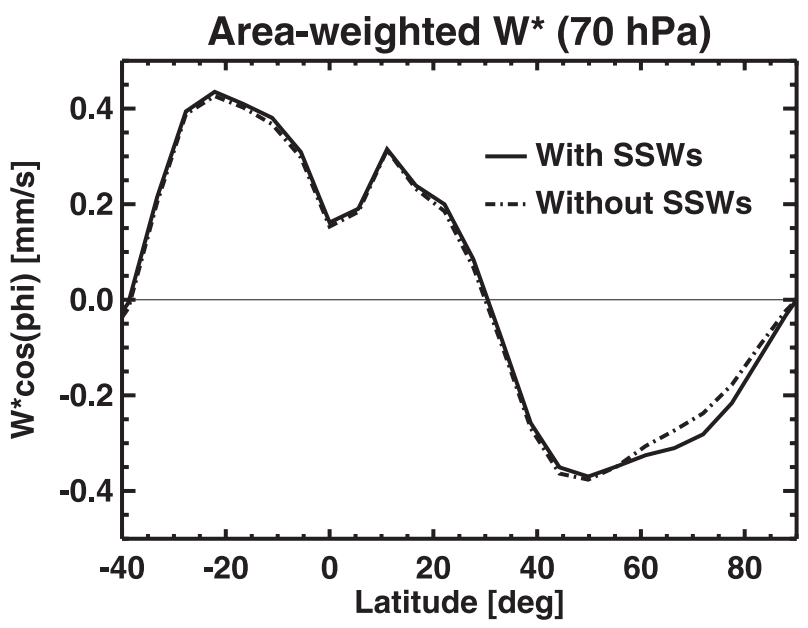

FIG. 14. Area-weighted residual vertical velocity $\bar{w}^{*}$ at $70 \mathrm{hPa}$ for DJF (1960-2004) for winters with and without SSWs for the REF2 ensemble average. SSWs are computed using the standard method. The latitudinal axis extends into the Southern Hemisphere to encompass the entire region of upwelling.

using the standard method is a consequence of changes in the underlying climatological mean winds, and is not related to changes in tropospheric wave forcing.

The final part of our study touches on the impact of SSWs on the Brewer-Dobson circulation. Winters with SSWs are found to have a $\sim 10 \%$ stronger net downward mass flux in the Northern Hemisphere than winters without. This value remains nearly constant over the course of the 150-yr simulation.

Our study shows that, at least for CMAM, the climate change-induced increase in frequency of SSWs defined using the standard method is a consequence of the absolute criterion employed, and that the future Arctic stratosphere can be most simply viewed as essentially unchanged variability superimposed on a weakened climatological polar night jet. Therefore, we suggest that in future model intercomparisons of the impact of climate change on SSWs, the NAM method be used in conjunction with the standard method. Otherwise, differences in model-predicted changes in the zonal mean state could lead to apparent differences in SSW frequency changes that have nothing to do with changes in variability. However, because intermodel comparisons using the NAM method are complicated by the likelihood that the underlying EOFs are different, this method should not be used for comparing SSW climatologies between different models. We also propose that the standard deviation of the daily zonal mean temperature and $100-\mathrm{hPa}$ heat flux anomalies be used as additional diagnostics for understanding the impact of climate change on stratospheric variability. Finally, we note that there is considerable natural variability in multidecadal

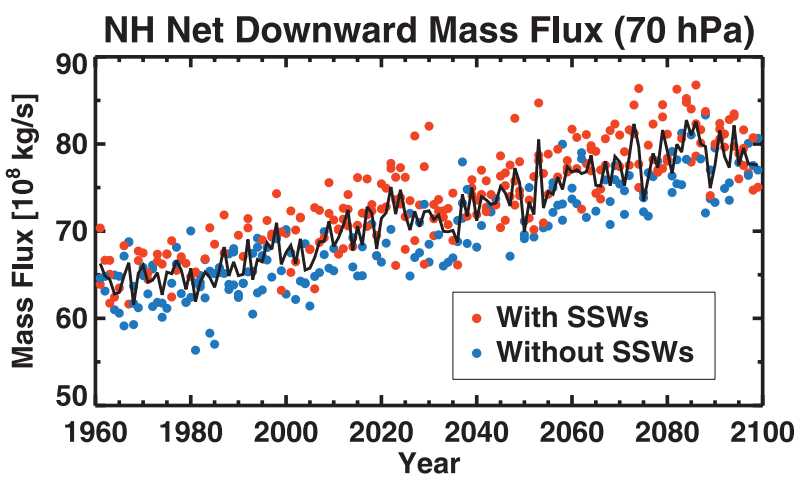

FIG. 15. Time series of the Northern Hemisphere net downward mass flux at $70 \mathrm{hPa}$ for DJF for the REF2 simulations. Colored circles denote years with (red) and without (blue) SSWs for each of the three simulations. The black line denotes the ensemble average. SSWs are computed using the standard method; the mass flux is computed as in McLandress and Shepherd (2009).

trends in SSW characteristics, illustrating that it is necessary to perform an ensemble of long simulations in order to reliably detect the effects of climate change on Arctic wintertime variability.

Acknowledgments. CM thanks Mark Baldwin for providing his EOF code and both Mark and Andrew Charlton-Perez for helpful discussions. The authors thank Thomas Reichler and Dave Thompson for their constructive reviews. This work was supported by the Canadian Foundation for Climate and Atmospheric Sciences through the C-SPARC project.

\section{REFERENCES}

Baldwin, M. P., and T. J. Dunkerton, 2001: Stratospheric harbingers of anomalous weather regimes. Science, 294, 581-584.

_ _ and D. W. J. Thompson, 2009: A critical comparison of stratosphere-troposphere coupling indices. Quart. J. Roy. Meteor. Soc., 135, doi:10.1002/qj.479.

Beagley, S. R., J. de Grandpré, J. N. Koshyk, N. A. McFarlane, and T. G. Shepherd, 1997: Radiative-dynamical climatology of the first-generation Canadian Middle Atmosphere Model. Atmos.-Ocean, 35, 293-331.

Butchart, N., J. Austin, J. R. Knight, A. A. Scaife, and M. L. Gallani, 2000: The response of the stratospheric climate to projected changes in the concentrations of well-mixed greenhouse gases from 1992 to 2051. J. Climate, 13, 2142-2159.

— the strength of the Brewer-Dobson circulation. Climate Dyn., 27, 727-741, doi:10.1007/s00382-006-0162-4.

Charlton, A. J., and L. M. Polvani, 2007: A new look at stratospheric sudden warmings. Part I: Climatology and modeling benchmarks. J. Climate, 20, 449-469.

_ - and Coauthors, 2007: A new look at stratospheric sudden warmings. Part II: Evaluation of numerical model simulations. J. Climate, 20, 470-488.

Charlton-Perez, A. J., L. M. Polvani, J. Austin, and F. Li, 2008: The frequency and dynamics of stratospheric sudden warmings in 
the 21st century. J. Geophys. Res., 113, D16116, doi:10.1029 2007JD009571.

de Grandpré, J., S. R. Beagley, V. I. Fomichev, E. Griffioen, J. C. McConnell, A. S. Medvedev, and T. G. Shepherd, 2000: Ozone climatology using interactive chemistry: Results from the Canadian middle atmosphere model. J. Geophys. Res., 105, 26 475-26 491.

Eyring, V., D. E. Kinnison, and T. G. Shepherd, 2005: Overview of planned coupled chemistry-climate simulations to support upcoming ozone and climate assessments. SPARC Newsletter, No. 25, WCRP SPARC, 11-17.

- , and Coauthors, 2006: Assessment of temperature, trace species, and ozone in chemistry-climate model simulations of the recent past. J. Geophys. Res., 111, D22308, doi:10.1029/ 2006JD007327.

—, and Coauthors, 2007: Multimodel projections of stratospheric ozone in the 21st century. J. Geophys. Res., 112, D16303, doi:10.1029/2006JD008332.

Hitchcock, P., T. G. Shepherd, and C. McLandress, 2009: Past and future conditions for polar stratospheric cloud formation sim- ulated by the Canadian Middle Atmosphere Model. Atmos. Chem. Phys., 9, 483-495.

Kalnay, E., and Coauthors, 1996: The NCEP/NCAR 40-Year Reanalysis Project. Bull. Amer. Meteor. Soc., 77, 437-471.

Limpasuvan, V., D. W. J. Thompson, and D. L. Hartmann, 2004: The life cycle of the Northern Hemisphere sudden stratospheric warmings. J. Climate, 17, 2584-2596.

McLandress, C., and T. G. Shepherd, 2009: Simulated anthropogenic changes in the Brewer-Dobson circulation, including its extension to high latitudes. J. Climate, 22, 1516-1540.

Scinocca, J. F., N. A. McFarlane, M. Lazare, J. Li, and D. Plummer, 2008: The CCCma third generation AGCM and its extension into the middle atmosphere. Atmos. Chem. Phys., 8, 7055-7074

Taguchi, M., and D. L. Hartmann, 2006: Increased occurrence of stratospheric sudden warmings during El Niño as simulated by WACCM. J. Climate, 19, 324-332.

Waugh, D. W., and V. Eyring, 2008: Quantitative performance metrics for stratospheric-resolving chemistry-climate models. Atmos. Chem. Phys., 8, 5699-5713. 